\title{
Association of ghrelin and leptin with reproductive hormones in constitutional delay of growth and puberty
}

\author{
Mervat M El-Eshmawy ${ }^{1 *}$, Ibrahim A Abdel Aal ${ }^{2}$, Amany K El hawary ${ }^{3}$
}

\begin{abstract}
Background: Constitutional delay of growth and puberty (CDGP) is a variation of the onset and timing of pubertal development without a defined endocrine abnormality. Recently published studies indicate that leptin and ghrelin play a role in puberty initiation and progress. They have been implicated in regulation of GnRH secretion, with ghrelin having inhibitory and leptin, facilitatory effects. We hypothesized that elevated ghrelin and reduced leptin concentrations could be implicated in altering the tempo of puberty in adolescents with CDGP. So in the current study we evaluate variations in leptin and ghrelin levels in adolescent boys with CDGP, the relationships between both hormones and reproductive hormones including LH, FSH and testosterone were also evaluated.

Methods: The study enrolled 23 adolescent boys with CDGP and 20 healthy controls matched for age and sex. Weight, height, BMI, testicular volume, bone age, bone age delay, serum FSH, LH, testosterone, leptin and ghrelin were assessed.

Results: Adolescent boys with CDGP had significantly lower leptin and higher ghrelin than normal controls. Leptin was positively correlated with BMI, bone age, testicular volume, FSH, LH and testosterone and negatively correlated with delayed bone age and ghrelin. Ghrelin was negatively correlated with BMI, bone age, testicular volume, FSH, $\mathrm{LH}$ and testosterone. With multiple regression analysis BMI, FSH, LH, testosterone and ghrelin remained independently correlated with leptin while BMI, LH and testosterone remained independently correlated with ghrelin.
\end{abstract}

Conclusion: Elevated serum ghrelin and decreased leptin concentrations and their associations with reproductive hormones may explain the sexual immaturity in adolescent boys with CDGP.

\section{Background}

Constitutional delay of growth and puberty (CDGP) is a disorder occurring in healthy adolescents who have short stature compared with their peers, delay in bone maturation and delayed puberty [1]. Most children with CDGP begin to deviate from the normal growth curve before age $2 \mathrm{yr}$, subsequently grow at a relatively normal velocity, and then have a delayed pubertal growth spurt [2]. In boys with CDGP, a testicular volume of 3-4 $\mathrm{ml}$ is first reached when they are more than 13.7 years old. The sleep related Luteinizing hormone $(\mathrm{LH})$ increase that characterizes the onset of puberty, is normally

\footnotetext{
* Correspondence: mervat2040@yahoo.com

'Internal Medicine Department, Mansoura Specialized Medical Hospital,

Faculty of Medicine, Mansoura University, Mansoura, Egypt

Full list of author information is available at the end of the article
}

present in CDGP. The LH response to Luteinizing hormone releasing hormone (LHRH) analogues is intermediate between that of hypogonadal patients and normal pubertal children [3]. CDGP represents the extreme tail of the normal distribution, aggregates in families [4] and is much more common in boys [5]. A suspected diagnosis of CDGP can be definitely confirmed only when puberty and the pubertal growth spurt finally do occur spontaneously, more than two standard deviations later than the normal mean age.

Pubertal development and fertility are determined by a multi-hormonal effect. Puberty is characterized by increasing concentrations of gonadal estradiol in girls and testosterone in boys, driven by increasing concentrations of pituitary gonadotrophins which are, in turn, regulated by gonadotrophin-releasing hormone $(\mathrm{GnRH})$

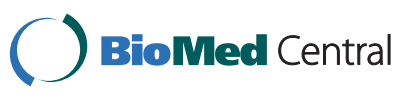


released by hypothalamic neurons [6,7]. A functional defect in any of the components of this hormonal complex directly affects puberty and reproduction in either gender. Recent research added two new members to this hormonal complex, namely leptin and ghrelin [8,9], which are secreted by adipose tissue and gastrointestinal tract, respectively. Besides their effect on carbohydrate and fat metabolism and appetite, these hormones acting on the hypothalamic-pituitary-gonadal axis, exert various effects on reproductive function [7].

Leptin, an adipocyte-derived hormone, is a key regulator of energy homeostasis and adiposity. It acts directly on hypothalamic nuclei to suppress food intake and increase energy expenditure [10]. In addition, leptin has been proposed to contribute to hypothalamic-pituitarygonadal function [11]. Indeed, leptin is clearly significant in pubertal development and progression in humans [12]; congenital leptin deficiency due to mutations in either the leptin gene or the leptin receptor gene, is associated with early-onset obesity and no pubertal development $[12,13]$.

Ghrelin is a 28 -amino acid peptide produced in a variety of human tissues; however the major source of circulating ghrelin is the stomach [14]. It regulates a large array of endocrine and non endocrine functions, including the control of growth hormone $(\mathrm{GH})$ secretion, food intake, energy balance and control of adiposity [15]. Ghrelin is the endogenous ligand for the GH secretagogue receptor (GHS-R) [14]. Together, ghrelin and growth hormone releasing hormone (GHRH) synergistically increase GH levels [16]. Ghrelin stimulates appetite and induces a positive energy balance that can lead to weight gain [17]. In addition, ghrelin reduces GnRH secretion in the pre-pubertal period [18].

The aim of the present study was to investigate the variations in leptin and ghrelin levels in adolescent boys with CDGP, the relationships between both hormones and reproductive hormones including LH, Follicle stimulating hormone (FSH) and testosterone were also evaluated.

\section{Methods}

The study comprised twenty three adolescent boys aged 14-16 years with CDGP (Table 1).

The diagnosis of CDGP was based on the following criteria:

1) Short stature (height less than 2SD below the mean)

2) Delayed puberty (onset delayed by more than $2 \mathrm{SD}$ that is, has not achieved $4 \mathrm{ml}$ testes until aged 14 years).

3) Bone age below the $10^{\text {th }}$ centile for chronological age (delayed by more than 1.5 years).
Table 1 Subjects characteristics

\begin{tabular}{lccc}
\hline Characteristics & $\begin{array}{c}\text { Adolescents with CDGP } \\
(\mathbf{n}=\mathbf{2 3})\end{array}$ & $\begin{array}{c}\text { Normal } \\
\text { control } \\
(\mathbf{n}=\mathbf{2 0})\end{array}$ & P-value \\
\hline Age (years) & $15.1+0.67$ & $15.1+0.72$ & 0.9 \\
Weight (kg) & $38.5+3.1$ & $64.3+13.36$ & $<0.001^{*}$ \\
Standing height & $147.8+5.9$ & $169.55+9.9$ & $<0.001^{*}$ \\
(cm) & $17.6+0.9$ & $23.4+2.2$ & $<0.001^{*}$ \\
BMI (kg/m $\left.{ }^{2}\right)$ & $2.6+0.5$ & $11.6+2$ & $<0.001^{*}$ \\
Testicular & $12.7+0.5$ & $15.1+0.67$ & $<0.001^{*}$ \\
volume (ml) & $2.3+0.4$ & - & \\
Bone age (years) & & & \\
Bone age delay & $0.4+0.08$ & $5.1+0.7$ & $<0.001^{*}$ \\
(years) & $0.2+0.06$ & $4.3+0.7$ & $<0.001^{*}$ \\
FSH (iu/ml) & $0.06+0.02$ & $4.5+3.2$ & $<0.001^{*}$ \\
LH (iu/ml) & & & \\
$\begin{array}{l}\text { Testosterone } \\
\text { (ng/ml) }\end{array}$ & $3.06+0.6$ & $7.03+2.5$ & $<0.001^{*}$ \\
Leptin (ng/ml) & $276.4+58.9$ & $106.5+29.6$ & $<0.001^{*}$ \\
Ghrelin (ng/ml) & & &
\end{tabular}

CDGP: Constitutional delay of growth and puberty; BMI: Body mass index; FSH: Follicle stimulating hormone; LH: Luteinizing hormone; Data are expressed as mean \pm standard deviation; ${ }^{*} P$ is significant if $<0.05$.

3) Absence of other causes of delayed puberty on history, examination and investigations. None of the participants was taking any medication.

Height and weight were measured using standard procedures. Body mass index (BMI) was calculated from the weight in kilograms divided by the square of the height in meters. Pubertal stage was assessed according to the method of Tanner and Whitehouse [19]. Skeletal age was determined on left wrist radiographs using Greulich and Pyle method. Bone age delay was noted as the difference between skeletal and chronological age. Twenty healthy adolescent boys matched for age in the mid and late pubertal stage (3-5 Tanner stage) were evaluated as controls.

All adolescents with CDGP subsequently attain puberty either spontaneously (15 boys) or after induction of puberty ( 8 boys). They progress through puberty with increasing testicular volumes and pubertal staging.

\section{Hormone assays}

To assess episodic hormone secretion, $3 \mathrm{ml}$ fasting blood samples were collected at 20 minutes intervals for 3 hours and the separated sera were mixed for the quantitative determination of ghrelin, leptin, FSH, LH and testosterone. Seum leptin levels were estimated by an enzyme immunoassay test that follows a typical twoStep capture (sandwitch) assay. (Diagnostic Biochem Canada Inc, DBC). Serum ghrelin levels were estimated by enzyme immunoassay kit designed to detect a speci- 
fic peptide based on the principle of competitive enzyme immunoassay (DRG International inc., USA). FSH, LH and testosterone were determined using ECLIA electrochemiluminescent immunoassay through automated auto analyzer Elec Sys 2010 (Roche, Germany).

All subjects signed an informed consent to be included in our study. The study was approved by the local ethical committee.

\section{Statistical analysis}

Data were analyzed using SPSS statistical package version 10 (SPSS, Inc., Chicago, IL, USA). The quantitative data were presented as a mean and a standard deviation. For the qualitative data, student t-test was used to compare between two groups. Simple regression analysis was performed with leptin and ghrelin as the dependent variables and all other parameters as independent variables. Multiple regression analysis was also performed with leptin and ghrelin as the dependent variables and BMI, testicular volume, bone age, bone age delay, FSH, LH and testosterone as independent variables.

$\mathrm{P}$ value of $<0.05$ indicates significant results.

\section{Results}

\section{Clinical and biochemical characteristics of the study subjects}

Baseline characteristics of the adolescents with CDGP and age and sex matched controls are given in Table 1. Adolescent boys with CDGP had significantly lower body weight, height, BMI, testicular volume and bone age than controls. Bone age delay of the adolescent boys with CDGP was $2.3+0.4$ years.

$\mathrm{FSH}, \mathrm{LH}$, testosterone and leptin levels were significantly lower $(\mathrm{p}<0.001)$ in adolescent boys with CDGP than controls. Ghrelin levels were significantly higher in the adolescent boys with CDGP than controls ( $\mathrm{p}<$ 0.001 ).

\section{Correlations between leptin levels and all other parameters}

Leptin levels were positively correlated with height, weight, testicular volume, bone age, FSH $(\mathrm{p}=0.04), \mathrm{LH}$ $(\mathrm{p}=0.038)$ and testosterone $(\mathrm{p}=0.039)$, and negatively correlated with bone age delay $(\mathrm{p}=0.012)$ and ghrelin $(\mathrm{p}=0.005)$ Table 2.

\section{Correlations between ghrelin levels and all other parameters}

Ghrelin levels were negatively correlated with height, weight, BMI, testicular volume, bone age, FSH ( $\mathrm{p}=$ $0.03), \mathrm{LH}(\mathrm{p}=0.01)$ and testosterone $(\mathrm{p}=0.032)$, and positively correlated with bone age delay $(\mathrm{p}=0.008)$ Table 3.
Table 2 Correlation between leptin and cinical and biochemical parameters in adolescents with CDGP

\begin{tabular}{lcc}
\hline Parameters & R & P- value \\
\hline Age (years) & 0.13 & 0.5 \\
Weight (kg) & 0.62 & $<0.001^{*}$ \\
Height (cm) & 0.79 & $0.002^{*}$ \\
BMI (kg/m ${ }^{2}$ ) & 0.87 & $<0.001^{*}$ \\
Testicular volume(ml) & 0.37 & $0.049^{*}$ \\
Bone age(years) & 0.52 & $0.011^{*}$ \\
Bone age delay(years) & -0.47 & $0.012^{*}$ \\
FSH (iu/ml) & 0.44 & $0.04^{*}$ \\
LH (iu/ml) & 0.42 & $0.038^{*}$ \\
Testosterone (ng/ml) & 0.43 & $0.039^{*}$ \\
Ghrelin (ng/ml) & -0.56 & $0.005^{*}$
\end{tabular}

CDGP: Constitutional delay of growth and puberty; BMI: Body mass index; FSH: Follicle stimulating hormone; LH: Luteinizing hormone; ${ }^{*} \mathrm{P}$ is significant if $<0.05$.

Multiple regression analysis with leptin and ghrelin as the dependent variables and other parameters as the independent variables

A multiple regression analysis to assess the independent effect of studied variables (BMI, testicular volume, bone age, bone age delay, $\mathrm{FSH}, \mathrm{LH}$, testosterone) on both leptin and ghrelin levels was also performed. BMI $(\beta=$ 0.77, $\mathrm{p}=0.002)$, FSH $((\beta=0.64, \mathrm{p}=0.03), \mathrm{LH}((\beta=$ $0.66, \mathrm{p}=0.02)$, testosterone $(\beta=0.41, \mathrm{p}=0.009)$ and ghrelin $(\beta=-0.55, \mathrm{p}=0.01)$ remained independently correlated with leptin levels while BMI $(\beta=-1.13, \mathrm{p}=$ $0.005), \mathrm{LH}(\beta=-0.62, \mathrm{p}=0.01)$ and testosterone $(\beta=-$ $0.82, \mathrm{p}=0.007)$, remained independently correlated with ghrelin levels.

\section{Discussion}

Puberty constitutes a distinct developmental stage characterized by physiological, anatomical and psychological alterations and comprises a preparatory step for

Table 3 Correlation between ghrelin and cinical and biochemical parameters in adolescents with CDGP

\begin{tabular}{lcc}
\hline Parameters & R & P- value \\
\hline Age (years) & -0.15 & 0.4 \\
Weight $(\mathrm{kg})$ & -0.39 & $0.03^{*}$ \\
Height (cm) & -0.48 & $0.02^{*}$ \\
BMI (kg/m ${ }^{2}$ ) & -0.46 & $0.02^{*}$ \\
Testicular volume(ml) & -0.43 & $0.04^{*}$ \\
Bone age(years) & -0.35 & $0.043^{*}$ \\
Bone age delay(years) & 0.53 & $0.008^{*}$ \\
FSH (iu/ml) & -0.45 & $0.03^{*}$ \\
LH (iu/ml) & -0.49 & $0.01^{*}$ \\
Testosterone (ng/ml) & -0.39 & $0.032^{*}$ \\
\hline
\end{tabular}

CDGP: Constitutional delay of growth and puberty; BMI: Body mass index; FSH: Follicle stimulating hormone; LH: Luteinizing hormone; ${ }^{*} \mathrm{P}$ is significant if $<0.05$. 
reproduction. Age at puberty is determined by genetic and environmental factors. CDGP is a variation of the onset and timing of pubertal development without a defined endocrine abnormality. Recently published results showed that both leptin and ghrelin have a role in $\mathrm{GnRH}$ production at different reproductive stages $[18,20,21]$; they showed opposing effects on pulsatile GnRH secretion [18]. We hypothesized that low leptin and high ghrelin concentrations could be implicated in altering the tempo of puberty in adolescents with CDGP.

In the present study, leptin levels were significantly lower in adolescent boys with CDGP than in normal controls. Our results also showed significant positive correlations between leptin levels and weight, BMI, FSH, $\mathrm{LH}$ and testosterone. These results are consistent with previous reports of low leptin concentrations in boys with CDGP [22,23]. Bideci et al. [22] also demonstrated a statistically significant relationship between leptin levels and hight, weight, BMI and bone age, they suggested that the reason of short stature and pubertal delay may be the decrease in weight which also the cause of low leptin level.

Leptin is clearly significant in pubertal development and progression [12,24]. Mantzoros et al. [25] showed that leptin levels increase by approximately $50 \%$ before the onset of puberty in healthy boys before testosterone, $\mathrm{LH}$, or FSH increases and decrease to baseline values after the initiation of puberty, which may indicate a role for leptin in pubertal initiation. However, Ozata et al. [26] found that leptin seems not to be a primary signal for the onset of puberty: instead it may act in a permissive way as one of several metabolic factors. In parallel with the ob/ob mouse, humans who have rare mutations of the leptin gene and are very obese remain prepubertal [12] unless they are given recombinant leptin which restores pulsatile gonadotropin secretion [27]. Furthermore, obese children have early puberty that could be the effect of high circulating levels of leptin [28].

Leptin regulates the hypothalamus-pituitary-gonad axis at both the central and gonadal levels [29]. Leptin stimulates $\mathrm{LH}$ and $\mathrm{FSH}$ in pituitary gonadotrophes [30] and also implicated in steroidogenesis in the gonads [31]. Stimulation of reproductive neuroendocrine output is also associated with increased circulating levels of leptin [32]. Adipocytes specifically bind androgens [33] and appear to carry androgen receptors [34]. Morelli et al. [35] suggested that androgens (adequate hormonal status) could have a positive effect on GnRH neuronal activity by synergizing with leptin (adequate energy status) in the regulatory mechanisms required for reproductive and sexual fitness.

As expected we found significant elevation of ghrelin concentrations in adolescent boys with CDGP compared to healthy controls. Our results also showed significant negative correlations between ghrelin and BMI, LH and testosterone. Our results were in parallel with many studies which demonstrated negative and significant correlations between ghrelin and $\mathrm{LH}$ and testosterone [15,36,37]. Also, Pomerants et al. [38] found decreased fasting ghrelin concentration and negative correlations between its level and body weight, BMI, lean body mass and testosterone concentrations in healthy pubertal boys.

Ghrelin inhibits GnRH [18] and LH secretions [36] in the pre-pubertal period. Moreover, the ghrelin and its receptors have been demonstrated in mature Leydig and Sertoli cells of rat and human testis [39]. Tena-Sempere $[15,37]$ showed that ghrelin could reduce circulating steroid hormones in pre-pubertal male rats.

It is thought that a degree of body fat is required for initiation of puberty and maintenance of reproductive function in mammals. In humans, the influence of nutrition and body composition on puberty and reproductive physiology has long been recognized [40]. CDGP subjects are typically underweight for height, either due to decreased energy intake [41] or increased energy expenditure [42]. In our study the BMI of the adolescent boys with CDGP were lower than that of the control group, it could be concluded that adipose tissue is unable to maintain adequate leptin production when a higher leptin secretion is required.

Moreover, previous reports show that ghrelin level is negatively correlated with body mass index [43] and weight loss increases circulating ghrelin levels [44]. This increase in ghrelin level may occur as an adaptive response to correct the abnormal energy status. Ghrelin may function as a signal communicating the nutrition states of the body to the central nervous system, Abou Heif et al. [45] reported that ghrelin could be one of the hormones responsible for the suppression of male reproductive axis in case of negative energy balance. So the inappropriately low leptin and high ghrelin secretions could contribute to the relevant state.

Multiple regression analysis revealed that leptin was negatively correlated with ghrelin. Leptin dose-dependently inhibits ghrelin transcription in vitro [46] and decreases ghrelin release from isolated rat stomach [47]. Komori et al. [48] provided a novel molecular link between leptin and ghrelin signaling through the leptin-induced negative regulatory element-binding protein which is an important regulator of GHS-R expression in the hypothalamus. So leptin and ghrelin, two hormones of opposing metabolic effects, could be considered as permissive signals possibly synergistically in the regulatory mechanisms required for reproductive and sexual fitness.

Ghrelin is the first identified hormone that increases feeding when administered peripherally. Ghrelin 
administration stimulates secretion of growth hormone, increases food intake, and produces weight gain $[49,50]$. It remains to be determined whether the administration of ghrelin, ghrelin analogues, or small molecule agonists will be useful to treat conditions such as CDGP.

\section{Conclusions}

From the previous discussion it seems that the adiposederived hormone leptin and gastrointestinal-derived hormone ghrelin communicate information about metabolic status and body weight to the hypothalamus to initiate puberty, so ghrelin and leptin represent metabolic gate for puberty. Elevated serum ghrelin and decreased leptin concentrations and their associations with reproductive hormones may explain the sexual immaturity in adolescents with CDGP.

\section{List of abbreviations}

CDGP: Constitutional delay of growth and puberty; LH: Luteinizing hormone; LHRH: Luteinizing hormone releasing hormone; FSH: Follicle stimulating hormone; GH: Growth hormone; GHS-R: Growth hormone secretagogue receptor; GHRH: Growth hormone releasing hormone.

\section{Acknowledgements}

This research did not receive any specific grant from any funding agency in the public, commercial or not-for-profit sector.

\section{Author details}

'Internal Medicine Department, Mansoura Specialized Medical Hospital, Faculty of Medicine, Mansoura University, Mansoura, Egypt. ${ }^{2}$ Clinical Pathology Department, Faculty of Medicine, Mansoura University, Mansoura, Egypt. ${ }^{3}$ Pediatric Department, Mansoura pediatric Hospital, Faculty of Medicine, Mansoura University, Mansoura, Egypt.

\section{Authors' contributions}

MME drafted the manuscript, conceived the study, and participated in its design and coordination. IAA carried out the laboratory studies, AKE helped to draft the manuscript. All authors read and approved the final manuscript.

\section{Competing interests}

The authors declare that they have no competing interests.

Received: 28 October 2010 Accepted: 22 December 2010 Published: 22 December 2010

\section{References}

1. Prader A: Delayed adolescence. Clin Endocrinol Metab 1975, 4:143-155.

2. Sedlmeyer IL, Palmert MR: Delayed puberty: analysis of a large case series from an academic center. J Clin Endocrinol Metab 2002, 87:1613-1620.

3. Lampit M, Hochberg Z: Androgen therapy in constitutional delay of growth. Horm Res 2003, 59:270-275.

4. Toublanc JE, Roger M, Chaussain JL: Etiologies of late puberty. Horm Res 1991, 36:136-140.

5. Sedlmeyer IL, Hirschhorn JN, Palmert MR: Pedigree analysis of constitutional delay of growth and maturation: determination of familial aggregation and inheritance patterns. J Clin Endocrinol Metab 2002, 87:5581-5586.

6. Flier JS, Underhill LH: Gonadotropin-releasing hormone: role of pulsatile secretion in the regulation of reproduction. N Engl J Med 1986, 315:1459-1468.

7. Grumbach MM, Styne DM: Puberty: ontogeny, neuroendocrinology, physiology, and disorders. In Williams Textbook of Endocrinology. Edited by: Wilson JD, Foster DW. Philadelphia: WB Saunders Co; 1992:1139-1221.

8. Miller DW, Harrison JL, Brown YA, Doyle U, Lindsay A, Adam CL, Lea RG: Immunohistochemical evidence for an endocrine/paracrine role for ghrelin in the reproductive tissues of sheep. Reprod Biol Endocrinol 2005, 3:60.

9. Budak E, Fernandez Sanchez M, Bellver J, Bellver J, Cerveró A, Simón C, Pellicer A: Interactions of the hormones leptin, ghrelin, adiponectin, resistin, and PYY3-36 with the reproductive system. Fertil Steril 2006, 85:1563-1581.

10. Munzberg H, Bjornholm M, Bates SH, Myers MG Jr: Leptin receptor action and mechanisms of leptin resistance. Cell Mol Life Sci 2005, 62:642-652.

11. Rosenbaum M, Leibel RL: Leptin: a molecule integrating somatic energy stores, energy expenditure and fertility. Trends Endocrinol Metab 1989, 9:117-124.

12. Strobel A, Issad T, Camoin L, Ozata M, Strosberg AD: A leptin missense mutation associated with hypogonadism and morbid obesity. Nat Genet 1998, 18:213-215.

13. Clément K, Vaisse C, Lahlou N, Cabrol S, Pelloux V, Cassuto D, Gourmelen M, Dina C, Chambaz J, Lacorte JM, Basdevant A, Bougnères P, Lebouc $Y$, Froguel P, Guy-Grand B: A mutation in the human leptin receptor gene causes obesity and pituitary dysfunction. Nature 1998, 392:398-341.

14. Kojima M, Hosoda H, Date Y, Nakazato M, Matsuo H, Kangawa K: Ghrelin is a growth-hormone-releasing acylated peptide from stomach. Nature 1999, 402:656-660

15. Tena-Sempere M: Ghrelin: novel regulator of gonadal function. J Endocrinol Invest 2005, 28:26-29.

16. Hataya Y, Akamizu T, Takaya K, Kanamoto N, Ariyasu H, Saijo M, Moriyama K, Shimatsu A, Kojima M, Kangawa K, Nakao K: A low dose of ghrelin stimulates growth hormone $(\mathrm{GH})$ release synergistically with $\mathrm{GH}$ releasing hormone in humans. J Clin Endocrinol Metab 2001, 86:4552.

17. Cummings DE, Overduin J: Gastrointestinal regulation of food intake. J Clin Invest 2007, 117:13.

18. Lebrethon MC, Aganina A, Fournier M, Gerard A, Parent AS, Bourguignon JP: Effects of in vivo and in vitro administration of ghrelin, leptin and neuropeptide mediators on pulsatile gonadotrophin-releasing hormone secretion from male rat hypothalamus before and after puberty. J Neuroendocrinol 2007, 19:181-188.

19. Tanner JM, Whitehouse RH: Clinical longitudinal standards for height, weight, height velocity, weight velocity and stages of puberty. Arch Dis Child 1976, 51:170-179.

20. Vulliemoz NR, Xiao E, Xia-Zhang L, Germond M, Rivier J, Ferin M: Decrease in luteinizing hormone pulse frequency during a five-hour peripheral ghrelin infusion in the ovariectomized rhesus monkey. J Clin Endocrinol Metab 2004, 89:5718-5723.

21. Ponzo OJ, Reynoso R, Rimoldi G, Rondina D, Szwarcfarb B, Carbone S, Scacchi P, Moguilevsky JA: Leptin stimulates the reproductive male axis in rats during sexual maturation by acting on hypothalamic excitatory amino acids. Exp Clin Endocrinol Diabetes 2005, 113:135-138.

22. Bideci $A$, Cinaz $P$, Hasanoglu $A$, Tumer $L$ : Leptin, insulin-like growth factor (IGF)-1 and IGF binding protein-3 levels in children with constitutional delay of growth. J Pediatr Endocrinol Metab 2002, 15:41-46.

23. Gill MS, Hall CM, Tillmann T, Clyton PE: Constitutional delay in growth and puberty (CDGP) is associated with hypoleptinaemia. Clin Endocrinol 1999, 50:721-726.

24. Chehab FF, Lim ME, LU R: Correlation of the sterility defect in homozygous obese female mice by treatment with human recombinant leptin. Nat Genet 1996, 12:318-320.

25. Mantzoros CS, Flier JS, Rogal AD: longitudinal assessment of hormonal and physical alterations during normal puberty in boys $V$ Rising leptin levels may signal the onset of puberty. J Clin Endocrinol Metab 1997, 82:1066-1070.

26. Ozata M, Ozdemir IC, Licinio J: Human leptin deficiency caused by a missense mutation: multiple endocrine defects, decreased sympathetic tone, and immune system dysfunction indicate new targets for leptin action, greater central than peripheral resistance to the effects of leptin, and spontaneous correction of leptin-mediated defects. J Clin Endocrinol Metab 1999, 84:3686-3695.

27. Faroogi IS, Jebb $S A$, Langmack $G$, Lawrence $E$, Cheetham $C H$, Prentice AM, Hughes IA, McCamish MA, O'Rahill S: Effect of recombinant leptin therapy in a child with congenital leptin deficiency. N Engl J Med 1999, 341:879-884.

28. Himes JH: Examining the evidence for recent secular changes in the timing of puberty in US children in light of increases in the prevalence of obesity. Mol Cell Endocrinol 2006, 25:254-255:13-21. 
29. Pasquali R: Obesity and androgens: facts and perspectives. Fertil Steril 2006, 85:1319-1340.

30. Yu WH, Kimura M, Walczewska A, Karanth S, McCann SM: Role of leptin in hypothalamic-pituitary function. Proc Natl Acad Sci USA 1997, 94:1023-1028.

31. Caprio M, Isidori AM, Carta AR, Moretti C, Dufau ML, Fabbri A: Expression of functional leptin receptors in rodent leydig cells. Endocrinology 1999, 140:4939-4947.

32. Adam CL, Archer ZA, Miller DW: Leptin actions on the reproductive neuroendocrine axis in sheep. Reprod Suppl 2003, 61:283-97.

33. Xu X, De Pergola G, Björntorp P: The effects of androgens on the regulation of lipolysis in adipose precursor cells. Endocrinology 1990, 126:1229-1234.

34. Sjögren J, Li M, Björntorp P: Androgen hormone binding to adipose tissue in rates. Biochim Biophys Acta 1995, 1244:117-1120.

35. Morelli A, Fibbi B, Marini M, Silvestrini E, De Vita G, Chavalmane AK, Vignozzi L, Filippi S, Forti G, Vannelli GB, Maggi M: Dihydrotestosterone and leptin regulate gonadotropin-releasing hormone $(\mathrm{GnRH})$ expression and secretion in human GnRH-secreting neuroblasts. J Sex Med 2009, 6:397-407.

36. Fernández-Fernández $R$, Tena-Sempere M, Navarro VM, Barreiro ML, Castellano JM, Aguilar E, Pinilla L: Effects of ghrelin upon gonadotropinreleasing hormone and gonadotropin secretion in adult female rats: in vivo and in vitro studies. Neuroendocrinology 2005, 82:245-255.

37. Tena-Sempere M: Exploring the role of ghrelin as novel regulator of gonadal function. Growth Horm IGF Res 2005, 15:83-88.

38. Pomerants $T$, Tillmann $V$, Jürimäe J, Jürimäe T: Relationship between ghrelin and anthropometrical, body composition parameters and testosterone levels in boys at different stages of puberty. J Endocrinol Invest 2006, 29:962-967.

39. Fernandez-Fernandez R, Tena-Sempere M, Roa J, Castellano JM, Navarro VM, Aguilar E, Pinilla L: Direct stimulatory effect of ghrelin on pituitary release of $\mathrm{LH}$ through a nitric oxide-dependent mechanism that is modulated by estrogen. Reproduction 2007, 133:1223-1232.

40. Frisch RE: Pubertal adipose tissue: is it necessary for normal sexual maturation? Evidence from the rat and human female. Fed Proc 1980, 39:2395-2400.

41. Wudy SA, Hagemann S, Dempfle A, Ringler G, Blum WF, Berthold LD, Alzen G, Gortner L, Hebebrand J: Children with idiopathic short stature are poor eaters and have decreased body mass index. Pediatrics 2005, 116:e52-e57.

42. Han JC, Balagopal P, Sweeten S, Darmaun D, Mauras N: Evidence for hypermetabolism in boys with constitutional delay of growth and maturation. J Clin Endocrinol Metab 2006, 91:2081-2086.

43. Otto B, Cuntz U, Fruehauf E, Wawarta R, Folwaczny C, Riepl RL, Heiman ML, Lehnert P, Fichter M, Tschop M: Weight gain decreases elevated plasma ghrelin concentrations of patients with anorexia nervosa. Eur J Endocrinol 2001, 145:669-673.

44. Cummings DE, Weigle DS, Frayo RS, Breen PA, Ma MK, Dellinger EP, Purnell JQ: Plasma ghrelin levels after diet-induced weight loss or gastric bypass surgery. N Engl J Med 2002, 346:1623-1630.

45. Abou Heif HM, Deif MM, Abdel Aziz HK: Effect of food restriction on ghrelin in adult male rats and its relation to male reproductive hormones. Andrologia 2010, 42:97-105.

46. Zhao Z, Sakata I, Okubo Y, Koike K, Kangawa K, Sakai T: Gastric leptin, but not estrogen and somatostatin, contributes to the elevation of ghrelin mRNA expression level in fasted rats. J Endocrinol 2008, 196:529-538.

47. Kamegai J, Tamura H, Shimizu T, Ishii S, Sugihara H, Oikawa S: Effects of insulin, leptin, and glucagon on ghrelin secretion from isolated perfused rat stomach. Regul Pept 2004, 119:77-81.

48. Komori T, Doi A, Furuta H, Wakao H, Nakao N, Nakazato M, Nanjo K, Senba E, Morikawa Y: Regulation of Ghrelin Signaling by a Leptininduced Gene, Negative Regulatory Element-binding Protein, in the Hypothalamic Neurons. J Biol Chem 2010, 285:37884-3794.

49. Takaya K, Ariyasu H, Kanamoto N, Iwakura H, Yoshimoto A, Harada M, Mori K, Komatsu Y, Usui T, Shimatsu A, Ogawa Y, Hosoda K, Akamizu T, Kojima M, Kangawa K, Nakao K: Ghrelin strongly stimulates growth hormone release in humans. J Clin Endocrinol Metab 2000, 85:4908-4911.

50. Kojima M, Kangawa K: Ghrelin: structure and function. Physiol Rev 2005, 85:495-522. doi:10.1186/1477-7827-8-153

Cite this article as: El-Eshmawy et al:: Association of ghrelin and leptin with reproductive hormones in constitutional delay of growth and puberty. Reproductive Biology and Endocrinology 2010 8:153.

\section{Submit your next manuscript to BioMed Central and take full advantage of:}

- Convenient online submission

- Thorough peer review

- No space constraints or color figure charges

- Immediate publication on acceptance

- Inclusion in PubMed, CAS, Scopus and Google Scholar

- Research which is freely available for redistribution

Submit your manuscript at www.biomedcentral.com/submit
Ciomed Central 